City University of New York (CUNY)

CUNY Academic Works

2018

The Effect of Various Police Enforcement Actions on Violent

Crime: Evidence From a Saturation Foot-Patrol Intervention

Eric L. Piza

CUNY John Jay College

How does access to this work benefit you? Let us know!

More information about this work at: https://academicworks.cuny.edu/jj_pubs/218

Discover additional works at: https://academicworks.cuny.edu

This work is made publicly available by the City University of New York (CUNY).

Contact: AcademicWorks@cuny.edu 


\title{
The Effect of Various Police Enforcement Actions on Violent Crime: Evidence From a Saturation Foot- Patrol Intervention
}

Criminal Justice Policy Review $1-19$

(C) The Author(s) 2018 Reprints and permissions: sagepub.com/journalsPermissions.nav DOI: $10.1177 / 0887403417725370$ journals.sagepub.com/home/cjp

@SAGE

\author{
Eric L. Piza'
}

\begin{abstract}
The current study tests the crime prevention effect of different police actions conducted during a foot-patrol saturation initiative in Newark, New Jersey. Police actions were categorized into two typologies: enforcement actions (i.e., arrests, quality of life summonses and field interrogations) and guardian actions (i.e., business checks, citizen contacts, bus checks, and taxi inspections). Logistic regression models tested the effect of enforcement and guardian actions on crime during daily (i.e., 24-hr) periods as well as the intervention's operational (6:00 p.m.-2:00 a.m.) and nonoperational (2:00 a.m.-5:00 p.m.) periods. Analyses were conducted twice, once for the Operation Impact target area and once for a surrounding catchment zone (to measure spatial displacement). Findings suggest that guardian actions had a greater crime prevention effect than enforcement actions on crime occurrence. Policy implications of the findings are discussed.
\end{abstract}

\section{Keywords}

crime and place, foot patrol, police enforcement, hot spots policing, guardianship

\section{Introduction}

While traditional police activities can be classified as largely reactive, recent decades have seen increased emphasis on proactive strategies incorporating high levels of focus and a diversity of approaches (Weisburd \& Eck, 2004). This change in mission

John Jay College of Criminal Justice, City University of New York, New York City, USA

\section{Corresponding Author:}

Eric L. Piza, John Jay College of Criminal Justice, City University of New York, 524 W. 59th Street, Haaren Hall Room 636.15, New York, NY 10019, USA.

Email: epiza@jjay.cuny.edu 
has resulted in the emergence of police strategies with significant evidence of effectiveness, with the strongest evidence found for geographically focused police practices (Braga, Papachristos, \& Hureau, 2014; Skogan \& Frydl, 2004; Weisburd \& Eck, 2004). While there is general consensus on the effectiveness of geographically focused practices, namely hot spots policing, much less is known regarding the precise actions police officers should take when engaged in such practices.

There is general agreement that proactive police actions generate greater crime control benefits than the predominately reactive standard model of policing. However, police proactivity is not a singular action, but rather includes a "wide gamut of activities" (Wu \& Lum, 2016, pp. 1-2). On one hand, proactivity can take the form of formal enforcement actions such as arrests, summonses, or field interrogation tactics (Piza, Caplan, Kennedy, \& Gilchrist, 2015; Rosenfeld, Deckard, \& Blackburn, 2014; Sherman \& Rogan, 1995b). On the other hand, police could affect crime through their visual presence in hot spots and informal engagement with residents, relying less on punitive enforcement (Nagin, Solow, \& Lum, 2015; Sherman \& Weisburd, 1995; Telep, Mitchell, $\&$ Weisburd, 2014). Little is known regarding which of these types of proactivity most directly affects crime occurrence. This is an important gap in the literature for several reasons. First, despite observed typologies of police practices (e.g., Hot Spots Policing, Problem-Oriented Policing, etc.), individual interventions can vary greatly in terms of police officer enforcement expectations. Second, police officers are afforded a great deal of discretion in addressing public safety concerns, with a number of enforcement options typically available in any given situation. For these reasons, knowing the specific officer actions that maximize program effect can greatly inform police strategy.

The current study contributes to the literature by testing the crime prevention effect of various police officer enforcement actions during the Newark, New Jersey Police Department's (NPD) Operation Impact, a foot-patrol saturation initiative. Police actions were categorized into two typologies: official "enforcement actions" and less punitive, more informal "guardian actions." Logistic regression models tested whether these enforcement typologies differentially affected violent crime levels in target and catchment areas. Findings on the relative effect of various enforcement actions can have important implications for the design and implementation of geographically focused police strategies. Specifically, such findings can help police determine whether traditional law enforcement activities can be de-emphasized in favor of less invasive actions, which may help strike a balance between crime prevention and fostering positive police/community relations. This issue is particularly salient in the current study setting of Newark, as a recent investigation conducted by the Department of Justice (DOJ) found that aggressive enforcement activities disproportionately affected minority communities and impinged upon civil liberties in certain contexts (U.S. Department of Justice Civil Rights Division, 2014).

\section{Review of Relevant Literature}

Contemporary policing has seen an increased understanding of the programs and practices that effectively prevent crime and disorder. The National Academy of Sciences' 
Committee to Review Research on Police Policy and Practices systematically reviewed policing studies in response to the U.S. DOJ's considerable investment in law enforcement practice and research under the 1994 crime act (Skogan \& Frydl, 2004). The committee concluded that highly focused interventions at crime hot spots "provide the strongest collective evidence of police effectiveness that is now available" (Skogan \& Frydl, 2004, p. 250) with a recent systematic review and meta-analysis providing further support for hot spots policing (Braga et al., 2014).

The effect of hot spots policing is contextualized through a comparison with the standard model of police practice, which emphasizes reactive responses to crime and rigid adherence to traditional law enforcement tools, such as random patrol, rapid response, and retroactive investigations (Skogan \& Frydl, 2004). Hot spots policing conversely emphasizes the proactive disruption of crime and disorder by targeting the micro-places that disproportionately generate public safety problems. However, lost in these findings is the fact that hot spots policing varies greatly in scope. For example, studies included in Braga and colleagues' (2014) systematic review incorporated a diverse set of tactics including situational crime prevention (Braga \& Bond, 2008), proactive traffic stops (Sherman \& Rogan, 1995b), raids on drug houses (Sherman \& Rogan, 1995a), collaborative problem-solving with businesses and/or residents (Taylor, Koper, \& Woods, 2011; Weisburd \& Green, 1995), directed motor vehicle patrol (Taylor et al., 2011), and foot patrol (Ratcliffe, Taniguchi, Groff, \& Wood, 2011), among others.

In addition, street-level actions enacted by police officers can exhibit a great deal of variability even within single interventions. Police officer actions are not situationally dictated, as research suggests as much as $37 \%$ to $86 \%$ of a patrol officer's shift comprises "uncommitted time" not spent on responding to calls for service, making arrests, or engaging in other administrative duties (Famega, 2005). Hence, officers enjoy a great deal of latitude when choosing how to address incidents of concern, with a number of appropriate enforcement decisions available in most instances (Schafer, Carter, Katz-Bannister, \& Wells, 2006). While such observations have typically been made in the context of general patrol deployment, hot spots policing seemingly provides a similar amount of leeway to officers. For example, following an inspection visit during the Minneapolis Hot Spots Policing experiment (Sherman \& Weisburd, 1995), George Kelling reported witnessing a range of police officer activities, with some officers "reading newspapers or sunning themselves while sitting on the patrol car, while others were engaging citizens in friendly interaction in community-policing style" (Sherman \& Weisburd, 1995, p. 634).

The findings of Sherman and Weisburd (1995) raise an interesting question. The experiment generated significant crime reductions while placing no emphasis on the nature of police activity within hot spots. More recent place-based policing efforts have similarly generated significant crime reductions without emphasizing specific officer behaviors (e.g., Novak, Fox, Carr, \& Spade, 2016, p. 468). This suggests the possibility that the visible presence of police and minimally invasive contacts with the community may matter as much as formal law enforcement activities. Recent studies also suggest the joint importance of officer presence and enforcement actions. For 
example, while Ratcliffe et al. (2011) reported formal foot-patrol officer actions such as pedestrian stops, vehicle stops, and arrests as process measures, they argued that the presence of patrol officers operated as a "certainty-communicating device" by which increased certainty of punishment is communicated to potential offenders. Ratcliffe et al. (2011, p. 823, Footnote 19) further acknowledged that informal, communityoriented activity, which does not readily lend itself to reporting, may have contributed to the crime reduction. Telep et al. (2014) conducted an experiment in which police patrols were shifted to different hot spots every $15 \mathrm{~min}$ in Sacramento. While the authors emphasized that their study did not seek to evaluate precisely what officers did in hot spots, findings of prior research suggests that a time frame of 15 min does not afford a great amount of time for officers to enact enforcement activities. Particularly relevant to the Sacramento experiment, Wu and Lum (2016) found that police officers in Jacksonville, Florida, spent an average of $40 \mathrm{~min}$ on each proactive enforcement activity. This suggests that officer presence and guardianship were likely the key preventive mechanisms in the Sacramento hot spots experiment (Telep et al., 2014).

Such research findings suggest a prevention mechanism through which police officers de-emphasize formal enforcement in favor of conspicuous presence and more informal community engagement. Nagin et al. (2015) described such an approach as the sentinel role of police. While Nagin et al. (2015) did not empirically test their theoretical model, recent research provides support for the sentinel role. Ariel, Weinborn, and Sherman (2016) tested the effect of patrol by uniformed civilian police staff with few arrest powers and no weapons (i.e., a purely sentinel role) in hot spots. The "soft patrol" by civilians was associated with 39\% less crime and 20\% less calls-for-service in target areas as compared with control areas, suggesting that crime reductions in hot spots are not contingent on "hard" police power. Furthermore, a recent systematic review and meta-analysis of Broken Windows interventions found the strongest program effect sizes were generated by community and problem-solving interventions while aggressive order maintenance strategies dependent on traditional law enforcement activities did not generate significant crime reductions (Braga, Welsh, \& Schnell, 2015).

Despite such research findings, it should be noted that police adhering to traditional law enforcement activities has been shown to generate significant crime control benefits, specifically when focused at high-crime places. The Kansas City Hot Spots Patrol experiment mandated that officers enact proactive motor vehicle and pedestrian stops in target areas, specifically in search of illegal firearm carrying, which generated significant reductions in gun crime (Sherman \& Rogan, 1995b). In an experiment pairing directed police patrol with proactive closed-circuit television monitoring, Piza et al. (2015) found that increased levels of enforcement in response to observed incidents of concern generated significant reductions in violent crime and social disorder. Rosenfeld et al. (2014) found that proactive arrests and traffic enforcement generated significant reductions in nondomestic firearm assaults. Additional support for enforcement manifests when contrasting two experiments conducted in Philadelphia (Groff et al., 2015; Ratcliffe et al., 2011). While Ratcliffe et al. (2011) found that foot patrol generated significant crime reductions at hot spots, Groff et al. (2015) found that foot patrol was not associated with any changes in crime occurrence. These divergent 
results may be at least partially attributed to different enforcement levels, with the rookie officers included in the foot-patrol experiment (Ratcliffe et al., 2011) generating increases in arrests, pedestrian stops, and vehicle stops and the veteran officers assigned to the foot-patrol condition in the police tactics experiment (Groff et al., 2015) not generating any increases in enforcement. Groff et al. (2015) suggested that this discrepancy in enforcement activity may explain foot patrol's differing effect on crime across the two experiments.

A review of the literature suggests "what exactly police should be doing in crime hot spots remains an open question" (Haberman, 2016, p. 489). While individual studies have compared the use of different police strategies within individual jurisdictions (Groff et al., 2015; Taylor et al., 2011), questions regarding police officer actions were not addressed. While overall strategies were established in hot spots, police officers may have enacted different actions in carrying out the strategy. For example, a given officer assigned to a directed patrol detail may most often arrest suspects when probable cause exists while another officer may use her or his discretion to use less punitive remedies to crime occurrence. The current study contributes to the literature by analyzing the effect of individual police officer actions on violent crime. Data come from the NPD's Operation Impact, a saturation foot-patrol intervention. As per the typical approach of place-based policing research, the classification of Operation Impact as a foot-patrol intervention seems straightforward. However, this classification does not account for the varying activities that the police officers conducted on a daily basis. The current study isolates the effect of these disparate officer actions on daily levels of violent crime.

\section{Method}

\section{Study Setting}

Newark is the largest city in New Jersey, spanning over 26 square miles with a population of nearly 280,000 persons according to the last decennial census. The percentage of residents living below the poverty level (29.7\%) is nearly 3 times that of New Jersey as a whole (10.8\%). Ethnic minorities largely comprise Newark's population with $52.4 \%$ of the population Black and $33.8 \%$ of residents identifying themselves as Hispanic or Latino (U.S. Census Bureau, 2010). The city has historically struggled with issues of gun violence. Internal police department data indicating that from 2007 to 2010 over $84 \%$ of murders resulted from a gunshot would while roughly half of all robberies involved a firearm (Piza \& O’Hara, 2014, p. 698).

Following the election of Cory Booker, Newark's first new mayor in nearly three decades, and the appointment of new police leadership in mid-2006, the NPD underwent a significant change in its overall strategy and mission. In their analysis of organizational changes within the NPD, Jenkins and DeCarlo (2015) found the aforementioned change in police leadership led to increased emphasis on increasing the number of police contact with citizens on the street, with supervisors and officers universally acknowledging the importance of combating street-level quality-of-life and drug market issues. In this vein, proactive enforcement aimed at street-level disorder and the illicit narcotics trade became the agency's primary strategy against violence. 


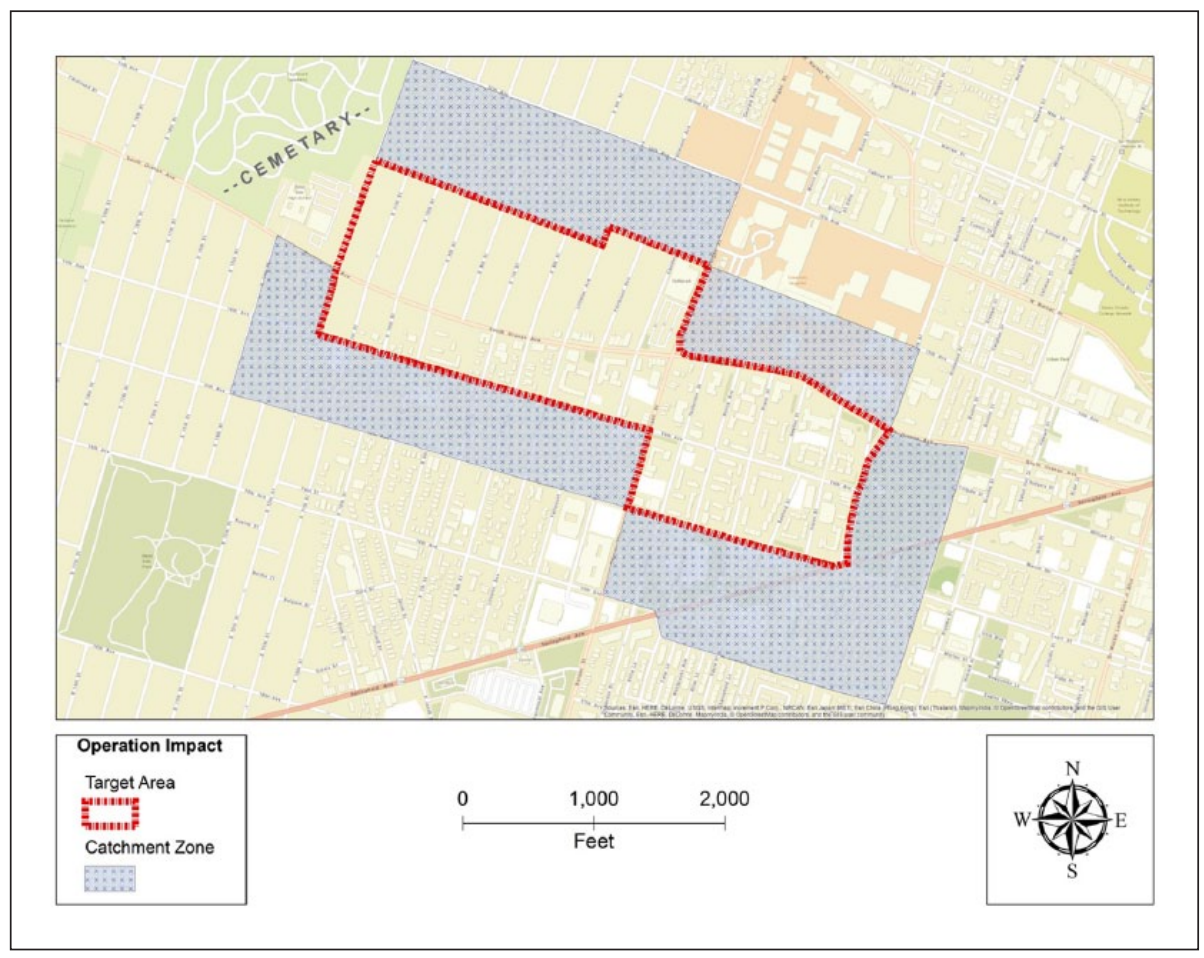

Figure I. Operation Impact target area and catchment zone.

Replicating an NYPD intervention of the same name (Smith \& Purtell, 2007), Operation Impact launched in June 2008 and epitomized the NPD's place-based approach to crime prevention. On a nightly basis, 12 police officers under the supervision of three supervisors patrolled the quarter-square-mile Operation Impact target area on foot (see Figure 1). Operation Impact represented a drastic increase in police presence within the target area, as Newark's police sectors (which averaged approximately 3-square-miles in size) were typically patrolled by two police officers (Piza \& O’Hara, 2014, pp. 693-694). A select group of officers were assigned to Operation Impact upon graduation from the police academy and remained detailed to the intervention until graduates from the ensuing academy class were selected as their successors. Supervisors were selected based on their levels of experience managing proactive enforcement units, such as "Gangs" or "Narcotics."

During foot patrols, officers were instructed to identify and disrupt street-level conditions that leadership believed may generate violent crime, such as social disorder and illicit narcotics activity. Given the emphasis on proactive activity, official enforcement actions were expected to take place on a frequent basis during the intervention. However, NPD commanders also recognized that, given their daily presence within the target area, foot-patrol officers could (and should) conduct additional activities to 
address criminogenic conditions. To readily collect such data, Operation Impact commanders created a custom after-action report measuring non-law enforcement actions (referred to as guardian actions in the current study) conducted by officers each shift. It is important to note the nature of the Operation Impact officer activities differed from standard patrols on two dimensions. First, Operation Impact officers were not tasked with regularly responding to citizen calls for service, except when all patrol cars assigned to the encompassing police sector were "out of service." Rather, the foot-patrol officers were expected to engage in proactive activities for the vast majority of their shifts. Second, official law enforcement actions were the benchmark commanders used to assess the performance of standard patrol officers. The guardian actions collected as part of Operation Impact were not systematically recorded by any other unit in the NPD, meaning that such data were not referenced in department-wide performance accountability sessions such as CompStat.

Foot patrols were conducted 7 days a week between the hours of 6:00 p.m. and 2:00 a.m. to coincide with times during which violence was at its peak. An evaluation by Piza and O'Hara (2014) supported the overall strategy of Operation Impact, though with some important caveats. The analysis found that overall street violence as well as the disaggregate categories of murder, shootings, and nondomestic aggravated assault significantly decreased in the target area absent any displacement effects. However, robbery suffered from substantial levels of both temporal and spatial displacement, showing Operation Impact to have differentially affected the various types of street violence.

\section{Data Sources and Analytical Strategy}

Data for this project focused on Operation Impact's 53-week implementation period spanning from June 5, 2008, to June 10, 2009. While Operation Impact lasted approximately 2 years, severe cuts in the department's budget caused a steady decline in the scope and dosage of the initiative beginning in the third quarter of 2009, in anticipation of pending police officer layoffs. The 53-week period represents the time when Operation Impact ran at full strength and is thus the most appropriate study period (Piza \& O’Hara, 2014). ${ }^{1}$

Crime incident data were measured from the NPD's Records Management System (RMS). To tailor the analysis to the type of street-level behavior targeted by Operation Impact, incidents not likely to be influenced by the intervention strategy (domestic assaults occurring indoors and student fights on school property) were excluded from the study, following the approach of Piza and O'Hara (2014). The analysis included three specific crime types: aggravated assault, murder, and robbery. The crime types were combined into a composite "Violent Crime" category to capture overall levels of violence. "Robbery" was included on its own as a crime category given its prevalence. "Assault and Murder" were included as a single category in light of murder's sparse occurrence (only two murders occurred in the target area during the study period). For each of three crime categories of interest, separate models were conducted to analyze three distinct temporal periods: 6:00 p.m. to 2:00 a.m. (Operation Impact's operational 
period), 2:00 a.m. to 5:00 p.m. (the nonoperational period), and a full 24-hr period (i.e., the entire day). This series of analyses was repeated twice: once measuring crime in the Operation Impact target area and once in the surrounding catchment zone for the purpose of measuring spatial displacement.

The independent variables in each model were the enforcement actions and guardian actions conducted by the Operation Impact officers. Officer actions were measured via after-action reports submitted by the foot-patrol officers upon the conclusion of each night's shift. Field sergeants then summed the individual officer activities to provide cumulative totals of daily activity within the Operation Impact target area. The use of after-action reports allowed for the measurement of the less formal proactive police activities that typically are not measured in police data systems (Wu \& Lum, 2016). In total, the after-action reports captured daily counts of seven unique officer actions: arrest, field interrogations, quality of life summonses, citizen contacts, business checks, bus checks, and taxi inspections. These activities are different in nature, varying in their degree of severity and emphasis on traditional law enforcement. These differences were accounted for in the analysis through the operationalization of police activity categories, as described subsequently.

Arrests, field interrogations, and quality of life summonses were jointly considered "Enforcement Actions." The data did not allow for the identification of arrest charges. However, given the proactive nature of Operation Impact and the emphasis on disrupting social disorder and narcotics-related activity, it can be assumed that the majority of arrests were of a low-level nature (i.e., misdemeanor arrests). Quality of life summonses are citations issued for behaviors commonly referred to as social disorder in the literature, such as drinking in public, gambling in public, and aggressive panhandling. Field interrogations refer to situations in which officer approaches a citizen due to reasonable suspicion of crime activity, as per the standards established by Terry $v$. Ohio (1968). For each field interrogation conducted, police officers submitted a stop report that articulates the reason for the stop.

Citizen contacts, business checks, bus checks, and taxi inspections were jointly considered "Guardian Actions" for the analysis. Similar to field interrogations, citizen contacts involve the interaction between police officers and citizens in the field. However, citizen contacts refer to incidents in which the contact was made for noncriminal reasons. In particular, the NPD asked the foot-patrol officers to build a rapport with the community by introducing themselves to citizens within the target area and explaining the purpose of the foot patrols. Citizen contacts also included instances in which citizens initiated contact with officers for purposes besides crime reporting. Business checks referred to incidents in which officers would enter a business to make contact with the employees and management on hand. Business checks allowed officers to build a rapport with the business community, similar to the goal of the citizen contacts, while also generating visible police presence in the vicinity immediately surrounding the business. Bus checks and taxi inspections involved the officers approaching these vehicles while they were stationary (e.g., at a red light, while parked, or otherwise idle) and making contact with the drivers and passengers. The goal of these inspections was similar to the business checks: They 
allowed for informal interaction between the foot-patrol officers and citizens, created opportunities for detection of criminogenic situations, and increased police presence in a targeted fashion. In the case of taxi inspections, this activity was informed by frequent robberies of taxi drivers during the preintervention period. Guardian actions are distinguished from enforcement actions due to their less punitive nature and emphasis on nonintrusive police presence, which fall within the scope of what Nagin et al. (2015) label as sentinel activities of police.

Last, a number of control variables were included to account for factors unrelated to Operation Impact that may have influenced crime occurrence. Enforcement actions (arrests, field interrogations, and quality of life summonses) conducted within the target area by NPD officers not associated with Operation Impact were collected from the RMS. Unfortunately, guardian actions were not systematically collected by the NPD outside of Operation Impact. However, while it is probable that units such as narcotics, gang, and vice conducted operations in the area, Operation Impact foot-patrol officers were the only proactive personnel deployed within the target area on a daily basis. Thus, motor vehicle patrol officers provided the only other daily presence in the area. Given that the motor vehicle patrol officers were primarily tasked with responding to citizen calls for service and taking action in response to observed crime events, their activity likely comprised of mostly enforcement actions. To control for officer activity occurring during the previous day, lagged 1-day variables were included for the NPD enforcement, as well as the Operation Impact enforcement and guardian actions. Two covariates were included as controls for features of weather that may influence streetlevel behavior. For each day, the median temperature and total inches of precipitation (rain or snow) were collected from the history archives of the Weather Underground website (www.wunderground.com/history). A binary variable measured whether each day fell on a weekend (Friday-Sunday) to reflect the heightened risk of crime during these days of the week (see Table 1 for descriptive statistics of all variables).

Units of analysis were the 371 days included in the study period to reflect the NPD's daily focus on proactive police activity. A series of logistic regression models were conducted to measure the effect of the enforcement actions and guardian actions on crime occurrence. In each model, the dependent variable was a binary measure reporting whether a crime occurred during the day in question (" 1 ") or not ("0"). ${ }^{2}$ To account for their different levels of occurrence, and to allow an easier comparison of their respective effects on the dependent variable, police activity variables were standardized to account for their different frequencies.

\section{Results}

Results of the analyses are reported below for each of the crime categories included in the study. Table 2 displays the results of the violent crime models. In the target area, a one-unit increase in guardian actions was associated with a $51 \%$ decreased likelihood of violent crime occurrence during the $24-\mathrm{hr}$ period and a $58 \%$ decreased likelihood of violent crime occurrence during the operational period. No variables achieved statistical significance in the catchment zone model. 
Table I. Descriptive Statistics of Crime Counts, Officer Actions, and Control Variables.

\begin{tabular}{|c|c|c|c|c|c|}
\hline Variable & M & $S D$ & Minimum & Maximum & Sum \\
\hline \multicolumn{6}{|c|}{ Dependent variables: Crime counts (target area) } \\
\hline \multicolumn{6}{|l|}{ Violent crime } \\
\hline 24-hr period & 0.20 & 0.45 & 0 & 3 & 74 \\
\hline Operational period & 0.10 & 0.30 & 0 & 1 & 36 \\
\hline Nonoperational period & 0.10 & 0.33 & 0 & 3 & 38 \\
\hline \multicolumn{6}{|l|}{ Robbery } \\
\hline 24-hr period & 0.13 & 0.36 & 0 & 2 & 49 \\
\hline Operational period & 0.06 & 0.23 & 0 & 1 & 21 \\
\hline Nonoperational period & 0.08 & 0.27 & 0 & 2 & 28 \\
\hline \multicolumn{6}{|l|}{ Assault and murder } \\
\hline 24-hr period & 0.07 & 0.25 & 0 & I & 28 \\
\hline Operational period & 0.05 & 0.24 & 0 & 2 & 18 \\
\hline Nonoperational period & 0.03 & 0.16 & 0 & 1 & 10 \\
\hline \multicolumn{6}{|c|}{ Dependent variables: Crime counts (catchment zone) } \\
\hline \multicolumn{6}{|l|}{ Violent crime } \\
\hline 24-hr period & 0.21 & 0.50 & 0 & 3 & 79 \\
\hline Operational period & 0.10 & 0.33 & 0 & 2 & 37 \\
\hline Nonoperational period & 0.11 & 0.34 & 0 & 2 & 42 \\
\hline \multicolumn{6}{|l|}{ Robbery } \\
\hline 24-hr period & 0.13 & 0.36 & 0 & 2 & 49 \\
\hline Operational period & 0.05 & 0.22 & 0 & 1 & 19 \\
\hline Nonoperational period & 0.08 & 0.28 & 0 & 2 & 30 \\
\hline \multicolumn{6}{|l|}{ Assault and murder } \\
\hline 24-hr period & 0.08 & 0.29 & 0 & 2 & 30 \\
\hline Operational period & 0.05 & 0.24 & 0 & 2 & 18 \\
\hline Nonoperational period & 0.03 & 0.18 & 0 & 1 & 12 \\
\hline \multicolumn{6}{|l|}{ Independent variables } \\
\hline Enforcement actions & 9.15 & 6.29 & 0 & 43 & 3,393 \\
\hline Guardian actions & 27.58 & 26.31 & 0 & 197 & $|0,23|$ \\
\hline \multicolumn{6}{|l|}{ Control variables } \\
\hline NPD enforcement & 5.00 & 4.77 & 0 & 27 & $\mathrm{I}, 855$ \\
\hline Median temperature & 55.22 & 17.96 & 13 & 87 & NA \\
\hline Precipitation (inches) & 0.19 & 0.62 & 0 & 5.68 & NA \\
\hline Weekend (Friday-Sunday) & 0.43 & 0.50 & 0 & I & NA \\
\hline
\end{tabular}

Note. NPD = New Jersey Police Department.

Table 3 displays the results of the robbery models. In the target area, a one-unit increase in the guardian actions was associated with a $52 \%$ decreased likelihood of robbery occurrence during the $24-\mathrm{hr}$ period and a $51 \%$ decreased likelihood of violent crime occurrence during the operational period. Lagged enforcement actions 
Table 2. Violent Crime Logistic Regression Findings.

\begin{tabular}{|c|c|c|c|c|c|c|c|c|c|}
\hline \multirow[b]{2}{*}{ Variable } & \multicolumn{3}{|c|}{ 24-hr period } & \multicolumn{3}{|c|}{ Operational period } & \multicolumn{3}{|c|}{ Nonoperational period } \\
\hline & OR & $S E$ & $p$ & OR & $S E$ & $p$ & OR & $S E$ & $p$ \\
\hline \multicolumn{10}{|l|}{ Target area } \\
\hline Enforcement actions & 0.98 & 0.14 & .91 & 0.82 & 0.14 & .26 & 1.17 & 0.20 & .36 \\
\hline Guardian actions & 0.49 & 0.11 & $.00 * *$ & 0.42 & 0.12 & $.00 * *$ & 0.67 & 0.16 & .10 \\
\hline NPD enforcement & 1.29 & 0.18 & .06 & 1.33 & 0.26 & .15 & 1.28 & 0.20 & .11 \\
\hline L.enforcement actions & 0.78 & 0.11 & .07 & 0.78 & 0.13 & .14 & 0.77 & 0.15 & .18 \\
\hline L.guardian actions & 0.87 & 0.13 & .35 & 0.83 & 0.13 & .23 & 0.87 & 0.20 & .53 \\
\hline L.NPD enforcement & 1.29 & 0.19 & .09 & 1.19 & 0.23 & .37 & 1.31 & 0.24 & .13 \\
\hline Median temperature & 0.94 & 0.14 & .68 & 0.81 & 0.17 & .31 & 1.06 & 0.18 & .71 \\
\hline Precipitation & 1.00 & 0.11 & .97 & 0.96 & 0.12 & .73 & 1.00 & 0.15 & .98 \\
\hline Weekend & 0.77 & 0.22 & .37 & 0.88 & 0.33 & .73 & 0.65 & 0.24 & .24 \\
\hline$N$ & 370 & & & 370 & & & 370 & & \\
\hline Log likelihood & -164.65 & & & -107.96 & & & -113.88 & & \\
\hline Wald $\chi^{2}$ & 16.33 & & & 16.68 & & & 10.04 & & \\
\hline Pseudo $R^{2}$ & .05 & & & .07 & & & .04 & & \\
\hline \multicolumn{10}{|l|}{ Catchment zone } \\
\hline Enforcement actions & 0.75 & 0.13 & .09 & 0.65 & 0.16 & .08 & 0.81 & 0.16 & .29 \\
\hline Guardian actions & 0.89 & 0.14 & .45 & 0.74 & 0.21 & .29 & 0.98 & 0.15 & .91 \\
\hline NPD enforcement & 1.01 & 0.14 & .93 & 0.83 & 0.13 & .26 & 1.13 & 0.20 & .48 \\
\hline L.enforcement actions & 1.10 & 0.17 & .53 & 1.06 & 0.18 & .72 & 1.13 & 0.22 & .53 \\
\hline L.guardian actions & 0.81 & 0.14 & .21 & 0.92 & 0.22 & .71 & 0.72 & 0.15 & .11 \\
\hline L.NPD enforcement & 1.22 & 0.16 & .14 & 1.34 & 0.22 & .08 & 1.04 & 0.17 & .79 \\
\hline Median temperature & 0.89 & 0.14 & .46 & 0.90 & 0.20 & .63 & 0.84 & 0.15 & .33 \\
\hline Precipitation & 0.99 & 0.11 & .93 & 1.06 & 0.14 & .66 & 0.95 & 0.12 & .69 \\
\hline Weekend & 0.69 & 0.20 & .21 & 0.84 & 0.33 & .66 & 0.54 & 0.20 & .10 \\
\hline$N$ & 370 & & & 370 & & & 370 & & \\
\hline Log likelihood & -166.77 & & & -108.84 & & & $-|20.3|$ & & \\
\hline Wald $\chi^{2}$ & 13.66 & & & 10.56 & & & 13.24 & & \\
\hline Pseudo $R^{2}$ & .03 & & & .04 & & & .03 & & \\
\hline
\end{tabular}

Note. All police activity variables were standardized to account for their differing levels of occurrence. "L." prefix prior to a variable denotes that the variable measures activity for the lagged I-day period. OR = odds ratio; NPD = New Jersey Police Department. $* p \leq .05 . * * p \leq .01$.

conducted by NPD officers outside of Operation Impact were associated with higher robbery occurrence in the target area during the nonoperational period $(\mathrm{OR}=1.47)$. A similar relationship was observed in the catchment zone during the operational period, with a one-unit increase in lagged NPD enforcement actions associated with a $69 \%$ increased likelihood of a robbery occurring.

Table 4 displays the results of the assault and murder models, which produced far fewer significant findings than the prior models. During the nonoperational period, a one-unit increase in NPD enforcement actions was associated with a $72 \%$ increased likelihood of crime occurrence within the target area. No other variables achieved statistical significance in the target area or catchment zone models. 
Table 3. Robbery Logistic Regression Findings.

\begin{tabular}{|c|c|c|c|c|c|c|c|c|c|}
\hline \multirow[b]{2}{*}{ Variable } & \multicolumn{3}{|c|}{ 24-hr period } & \multicolumn{3}{|c|}{ Operational period } & \multicolumn{3}{|c|}{$\begin{array}{c}\text { Nonoperational } \\
\text { period }\end{array}$} \\
\hline & OR & SE & $p$ & OR & $S E$ & $p$ & OR & $S E$ & $p$ \\
\hline \multicolumn{10}{|l|}{ Target area } \\
\hline Enforcement actions & 1.15 & 0.18 & .39 & 0.90 & 0.19 & .61 & 1.30 & 0.24 & .17 \\
\hline Guardian actions & 0.48 & 0.13 & $.01 * *$ & 0.49 & 0.18 & $.05^{*}$ & 0.60 & 0.17 & .07 \\
\hline NPD enforcement & 1.28 & 0.20 & .11 & 1.65 & 0.36 & $.02 *$ & 1.02 & 0.21 & .93 \\
\hline L.enforcement actions & 0.75 & 0.13 & .09 & 0.92 & 0.16 & .64 & 0.61 & 0.17 & .07 \\
\hline L.guardian actions & 0.88 & 0.16 & .46 & 0.77 & 0.14 & .16 & 0.92 & 0.25 & .75 \\
\hline L.NPD enforcement & 1.49 & 0.23 & .01 & 1.29 & 0.27 & .22 & 1.47 & 0.24 & $.02 *$ \\
\hline Median temperature & 1.02 & 0.19 & .90 & 0.98 & 0.28 & .96 & 1.04 & 0.22 & .84 \\
\hline Precipitation & 0.99 & 0.13 & .93 & 1.06 & 0.16 & .71 & 0.86 & 0.20 & .50 \\
\hline Weekend & 0.54 & 0.19 & .08 & 0.64 & 0.32 & .37 & 0.56 & 0.25 & .19 \\
\hline$N$ & 370 & & & 370 & & & 370 & & \\
\hline Log likelihood & -130.04 & & & -75.07 & & & -90.36 & & \\
\hline Wald $\chi^{2}$ & 20.48 & & & 16.05 & & & 17.22 & & \\
\hline Pseudo $R^{2}$ & .02 & & & .07 & & & .07 & & \\
\hline \multicolumn{10}{|l|}{ Catchment zone } \\
\hline Enforcement actions & 0.75 & 0.15 & .14 & 0.48 & 0.20 & .07 & 0.89 & 0.18 & .57 \\
\hline Guardian actions & 0.88 & 0.17 & .51 & 0.56 & 0.21 & .13 & 1.05 & 0.17 & .78 \\
\hline NPD enforcement & 1.04 & 0.17 & .81 & 0.68 & 0.15 & .08 & 1.20 & 0.22 & .32 \\
\hline L.enforcement actions & I.II & 0.17 & .49 & 1.08 & 0.23 & .74 & 1.17 & 0.21 & .38 \\
\hline L.guardian actions & 0.82 & 0.15 & .27 & 1.00 & 0.31 & .99 & 0.78 & 0.14 & .15 \\
\hline L.NPD enforcement & 1.25 & 0.19 & .13 & 1.69 & 0.35 & $.01 * *$ & 1.10 & 0.20 & .60 \\
\hline Median temperature & 0.84 & 0.15 & .33 & 0.91 & 0.28 & .76 & 0.81 & 0.16 & .28 \\
\hline Precipitation & 0.99 & 0.11 & .90 & 1.02 & 0.16 & .88 & 1.04 & 0.12 & .77 \\
\hline Weekend & 0.63 & 0.21 & .17 & 0.63 & 0.33 & .38 & 0.54 & 0.24 & .16 \\
\hline$N$ & 370 & & & 370 & & & 370 & & \\
\hline Log likelihood & -134.18 & & & -67.37 & & & -98.42 & & \\
\hline Wald $\chi^{2}$ & 13.14 & & & 21.22 & & & 10.05 & & \\
\hline Pseudo $R^{2}$ & .03 & & & .10 & & & .03 & & \\
\hline
\end{tabular}

Note. All police activity variables were standardized to account for their differing levels of occurrence. "L." prefix prior to a variable denotes that the variable measures activity for the lagged I-day period. OR = odds ratio; NPD = New Jersey Police Department.

$*_{p} \leq .05$. **p $\leq .01$.

\section{Discussion and Conclusion}

The current study sought to contribute to the ongoing debate regarding police officer actions during place-based interventions. Cumulative results suggest that guardian actions conducted by the foot-patrol officers were associated with significantly decreased likelihoods of overall violent crime and robbery occurrence within the target area. Every 1-unit increase in guardian actions was associated with a between 51\% and 58\% decreased likelihood of crime occurrence during the Operation Impact operational period and a between $51 \%$ and $52 \%$ decreased likelihood during the $24-\mathrm{hr}$ 
Table 4. Assault and Murder Logistic Regression Findings.

\begin{tabular}{|c|c|c|c|c|c|c|c|c|c|}
\hline \multirow[b]{2}{*}{ Variable } & \multicolumn{3}{|c|}{ 24-hr period } & \multicolumn{3}{|c|}{ Operational period } & \multicolumn{3}{|c|}{ Nonoperational period } \\
\hline & OR & SE & $p$ & OR & $S E$ & $p$ & OR & $S E$ & $p$ \\
\hline \multicolumn{10}{|l|}{ Target area } \\
\hline Enforcement actions & 0.75 & 0.17 & .21 & 0.83 & 0.23 & .50 & 0.76 & 0.34 & .54 \\
\hline Guardian actions & 0.58 & 0.20 & .12 & 1.03 & 0.29 & .92 & 1.06 & 0.39 & .88 \\
\hline NPD enforcement & 1.24 & 0.25 & .29 & 0.93 & 0.22 & .76 & 1.72 & 0.38 & $.02 *$ \\
\hline L.enforcement actions & 0.82 & 0.16 & .30 & 1.03 & 0.26 & .90 & 1.09 & 0.22 & .69 \\
\hline L.guardian actions & 0.86 & 0.27 & .64 & 0.82 & 0.24 & .51 & 0.68 & 0.31 & .39 \\
\hline L.NPD enforcement & 0.93 & 0.19 & .72 & 0.88 & 0.24 & .63 & 0.90 & 0.31 & .77 \\
\hline Median temperature & 0.81 & 0.16 & .29 & 1.01 & 0.30 & .98 & 1.22 & 0.26 & .36 \\
\hline Precipitation & 1.05 & 0.14 & .74 & 1.08 & 0.19 & .66 & 1.25 & 0.19 & .15 \\
\hline Weekend & 1.33 & 0.57 & .50 & 1.05 & 0.58 & .93 & 1.25 & 0.84 & .74 \\
\hline$N$ & 370 & & & 370 & & & 370 & & \\
\hline Log likelihood & -84.02 & & & -65.25 & & & -41.98 & & \\
\hline Wald $\chi^{2}$ & $|4.5|$ & & & 4.16 & & & 29.54 & & \\
\hline Pseudo $R^{2}$ & .05 & & & .01 & & & .09 & & \\
\hline \multicolumn{10}{|l|}{ Catchment zone } \\
\hline Enforcement actions & 0.77 & 0.19 & .28 & 0.83 & 0.23 & .50 & 0.71 & 0.20 & .41 \\
\hline Guardian actions & 0.88 & 0.22 & .62 & 1.03 & 0.29 & .92 & 0.65 & 0.29 & .33 \\
\hline NPD enforcement & 0.95 & 0.18 & .77 & 0.93 & 0.22 & .76 & 0.96 & 0.27 & .89 \\
\hline L.enforcement actions & 0.97 & 0.26 & .91 & 1.03 & 0.26 & .90 & 0.87 & 0.49 & .81 \\
\hline L.guardian actions & 0.74 & 0.22 & .32 & 0.82 & 0.24 & .51 & 0.63 & 0.41 & .48 \\
\hline L.NPD enforcement & 0.87 & 0.17 & .49 & 0.88 & 0.24 & .63 & 0.89 & 0.25 & .67 \\
\hline Median temperature & 1.04 & 0.23 & .88 & 1.01 & 0.30 & .98 & 1.06 & 0.33 & .85 \\
\hline Precipitation & 0.94 & 0.20 & .78 & 1.08 & 0.19 & .66 & 0.11 & 0.18 & .17 \\
\hline Weekend & 0.87 & 0.35 & .72 & 1.05 & 0.58 & .93 & 0.68 & 0.41 & .53 \\
\hline$N$ & 370 & & & 370 & & & 370 & & \\
\hline Log likelihood & -96.73 & & & -65.25 & & & -48.58 & & \\
\hline Wald $\chi^{2}$ & 5.01 & & & 4.16 & & & 4.93 & & \\
\hline Pseudo $R^{2}$ & .02 & & & .01 & & & .08 & & \\
\hline
\end{tabular}

Note. All police activity variables were standardized to account for their differing levels of occurrence. "L." prefix prior to a variable denotes that the variable measures activity for the lagged I-day period. OR = odds ratio; NPD = New Jersey Police Department. $* p \leq .05 . * * p \leq .01$.

period. Enforcement actions of the foot-patrol officers did not achieve statistical significance in a single instance. This suggests that the guardian actions conducted by the foot-patrol officers were more impactful than the enforcement actions.

It should also be noted that the enforcement actions conducted by NPD officers unassociated with Operation Impact may have generated negative effects within the target area. Findings suggest that the NPD enforcement actions may also have contributed somewhat to the spatial and temporal displacement detected in the evaluation of Piza and O'Hara (2014). Lagged NPD officer enforcement actions were associated with 69\% increased likelihood of robbery in the catchment zone during the operational period. NPD enforcement may have also contributed to temporal displacement, with one-unit increases 
associated with a $72 \%$ increased likelihood of assault and murder in the target area during the nonoperational period. Piza and O'Hara (2014) suggested that visible activity of officers within the Operation Impact target area may have contributed to displacement by providing offenders opportunities to relocate their criminal activities to nearby places and/or hours immediately preceding/following the operational period. However, Piza and O'Hara (2014) were referring to the foot-patrol officers and not patrol officers unassociated with Operation Impact, a suggestion not supported by the findings of the current study. It should also be noted that the activity of the NPD patrol officers is much more reactive than the activity of the foot-patrol officers in the target area. Therefore, the NPD enforcement findings may be more reflective of patrol officers responding to crime rather than their activity generating crime. This also highlights the limited crime prevention utility of reactive police units, as compared with proactive units such as the Operation Impact foot-patrol officers. In particular, given that proactive units are primarily tasked with disrupting street-level situations that can foster crime, they may more readily prevent crime than officers who primarily respond after crime occurrence.

When interpreting study findings, the reader should be aware of certain limitations inherent in the data and research design. Operation Impact was a very localized intervention tailored toward specific crime- and agency-related factors in Newark. In particular, the NPD devoted a very large amount of resources to the target area, with the 12 foot-patrol officers deployed nightly representing 6 times the number of officers typically deployed per shift within police sectors, which on average are 3 to 4 times the size of the Operation Impact target area. Therefore, the dosage of guardian actions delivered during Operation Impact may be very dissimilar to policing efforts in other contexts. The composition of the Operation Impact personnel is also unique, with the foot patrols comprised entirely of recent graduates from the police academy. While this reflected the approach of the original implementation of Operation Impact by the NYPD (see Smith \& Purtell, 2007), as well as foot-patrol operations in Philadelphia (Ratcliffe et al., 2011) and Kansas City (Novak et al., 2016), it is important to note that such heavy reliance on rookies may have affected the study findings. Such a situation was observed in Philadelphia, with rookie foot-patrol officers in one intervention (Ratcliffe et al., 2011) generating greater levels of enforcement and crime reduction than veteran foot-patrol officers in another (Groff et al., 2015).

In addition, while after-action reports provide the benefit of recording police actions not typically captured in official databases (Wu \& Lum, 2016), they also have some potential drawbacks. In particular, the guardian actions (business checks, citizen contacts, bus checks, and taxi inspections) were self-reported by foot-patrol officers and not verifiable by supervisors, given that the data are not recorded in any databases of the agency. While there is no reason to believe that officers systemically falsified information on their after-actions reports (as supervisors actively reviewed, and approved, the reports at the conclusion of each shift), it is possible that different officers may have different perceptions of what constitutes a specific guardian action (e.g., what one officer considered a citizen contact another officer may have considered a quick greeting from a pedestrian) and thus may report their activity in differential manners. Finally, it is worth mentioning that the data used in this study are quite 
dated, from nearly a decade ago. This is largely due to limitations of common police measures, with the type of guardian actions included in this study typically not readily captured in police databases. This required the author to collect, code, and digitize hard copies of after-action reports submitted by the foot-patrol officers. Such data collection activities are not always feasible in applied research. Nonetheless, researchers should seek to replicate this study using more recent data.

Despite these noted limitations, findings of the current study have important policy implications for contemporary policing. Since the Professional Era of the early-to-mid 1900s, American Policing has been defined by a warrior mind-set whereby police view themselves primarily as "crime fighters" (Rahr \& Rice, 2015). As such, enforcement actions (e.g., arrests, citations, stops, etc.) are largely considered the benchmark for measuring officer productivity under the guise that such actions generate reductions in crime (Sparrow, 2015). The current study adds support to recent arguments that proactive policing operations can incorporate less punitive officer actions without compromising effectiveness. Indeed, findings of the current study echo those of recent research supporting less invasive police actions (Ariel et al., 2016; Braga et al., 2015).

The emphasis on guardian actions over enforcement actions may be particularly appealing in light of recent events in American policing. The constitutionality of traditional enforcement actions, in particular, pedestrian stops and terry pats (i.e., stop question and frisk), has come under legal scrutiny. Perhaps nowhere has this issue been more publicly on display than in New York City, with the U.S. District court ruling that stops conducted by NYPD officers routinely violated the legal standards established by the Fourth Amendment of the constitution (Floyd et al. v. The City of New York, 2013). A similar issue was found in Newark, with the DOJ finding that stops conducted by NPD officers similarly violated constitutional standards (U.S. Department of Justice Civil Rights Division, 2014).

Outside of the legality of police enforcement actions, aggressive law enforcement tactics run the risk of damaging police-community relations. It should be noted that the lone experimental test of hot spots policing's potential backfire effects found that aggressive order maintenance had no significant impacts on citizen perceptions of police legitimacy (Weisburd, Hinkle, Famega, \& Ready, 2011). However, upon closer review of the study methodology, this randomized experiment may have low external validity, which scholars have noted in prior field experiments of policing (Eck, 2006) as well as in public policy research in general (Orr, 2015). During the controlled experiment, police officers administered an aggressive order maintenance strategy for $3 \mathrm{hr}$ per week at each target area over a 6-month period. Such a low dosage likely does not reflect intense place-based strategies as they are typically implemented by police, especially in high-crime cities. For example, intervention activities took place over 8 hr per day within Newark's Operation Impact target area. NYPD's version of Operation Impact occurred on a similarly frequent basis (Smith \& Purtell, 2007). In addition, officers in the Weisburd et al. (2011) study were instructed to primarily use warnings against persons observed acting disorderly, with enforcement actions reserved for repeat offenders and/or cases with aggravating circumstances (Weisburd et al., 2011, p. 305). This may not reflect standard practice, as police leaders often encourage 
enforcement actions not only due to the belief that they prevent crime but also because they offer a means of easily measuring officer productivity (Sparrow, 2015). Indeed, research focusing on established police practices, rather than field experiments, shows that aggressive enforcement actions can seriously damage police/community relations and perceptions of police legitimacy, particularly when such practices are applied in an unfocused manner (Fratello, Rengifo, Trone, \& Velaquez, 2013; Rengifo \& Fowler, 2016). In addition, a more recent field experiment of hot spots policing found that residents exposed to directed patrols experienced reported reductions in perceptions of procedural justice and trust in police as compared with residents in areas assigned to problem-solving or control conditions (Kochel \& Weisburd, 2017).

Given the potential drawbacks of aggressive enforcement, and the fact that less intrusive actions can generate comparable crime control benefits in certain contexts, police should consider more readily incorporating guardian actions into hot spots policing interventions. However, in the interest of generating more robust knowledge on the subject, researchers should continue to test the effect of such guardian actions, especially as compared with enforcement actions, through rigorous research. Researchers should capitalize on opportunities to conduct experimental tests of the relative effect of these actions in the field. One could envision such a study whereby officers deployed within specific hot spots utilize enforcement actions during their tours of duty while a different set of officers deployed within alternate hot spots can utilize guardian actions. To facilitate such a study, and minimize the threat for contamination, police officers with differing roles, responsibilities, and powers can be used to create various experimental conditions. For example, Ariel et al. (2016) found that the deployment of uniformed civilian police staff with minimal enforcement powers reduced crime and calls for service in target areas compared with control areas. Future research can compare the activity of such officers with an alternate treatment condition in which police officers employing more aggressive enforcement tactics operated within crime hot spots. To ensure generalizability of obtained results, such field experiments can be designed in a manner that ensures sample units are sufficiently similar to units that would permanently receive the treatment postexperimentation (see, for example, Tipton \& Peck, 2016).

Future empirical tests should also seek to uncover any interaction effects between guardian actions and enforcement actions. Said differently, when both types of actions are conducted simultaneously, the observed effect of one action may be at least partially bolstered by the occurrence of the other. In addition, while guardian actions may help build rapport with the community, it is possible that citizens may not be comfortable with such increased contact with police. In addition to exploring crime prevention effects, future research on guardian actions should also strive to better understand the nature of such police/community contacts and the subsequent impact on citizen satisfaction with police and perceptions of police legitimacy. Another important aspect of Operation Impact, and proactive policing in general, relates to patrol saturation levels. As previously discussed, the 12 foot-patrol officers deployed nightly represented a drastic increase in police presence, which begs the question of whether fewer officers deployed per shift could have generated similar crime reductions. Future research on 
hot spots policing may be able to shed light on such questions by randomly assigning different numbers of officers within various target areas to identify and determine whether any significant differences in effect were observed. In sum, given the track record of hot spots policing, researchers should move beyond testing whether such interventions generate crime reductions by focusing on the underlying mechanisms that may contribute to such effect.

\section{Declaration of Conflicting Interests}

The author(s) declared no potential conflicts of interest with respect to the research, authorship, and/or publication of this article.

\section{Funding}

The author(s) disclosed receipt of the following financial support for the research, authorship, and/or publication of this article: This paper was commissioned by the Misdemeanor Justice Project-Phase II funded by the Laura and John Arnold Foundation. Points of view or opinions contained within this document are those of the author and/or the participants and do not necessarily represent the official position or policies of the Laura and John Arnold Foundation and the Misdemeanor Justice Project.

\section{Notes}

1. While it would have been interesting to incorporate the entire 2-year period as the study period, allowing for a test of how resource reductions affected crime occurrence, officer activity data were only readily available for the first 53 weeks of the intervention. To review, officer activity data were reported at the conclusion of each shift via paper afteraction reports. While these reports were faxed to the NPD's Operations Bureau on a daily basis, they were never systematically digitized or entered into any centralized database. To conduct this analysis, the author had to create and manually enter the information from each after-action report into a database. Given time and resource constraints, the author was only able to review after-action reports for the first 53 weeks, to reflect the study period of the original Operation Impact evaluation (Piza \& O'Hara, 2014).

2. Given that Operation Impact tours crossed midnight (i.e., occurred in two separate days), it is helpful to discuss the operationalization of the binary variable at this point. Each day's nonoperational period was considered as temporally subsequent to the operational period. Said differently, the operational period was considered as the 8-hr period of 6:00 p.m. to 1:59 a.m. and the nonoperational period was considered the subsequent 8 -hr period (2:00 a.m. to 5:59 p.m.). Data were coded in this manner to reflect that NPD's emphasis on having officers identify and disrupt criminogenic situations as they occur. Therefore, the nonoperational period reflects the point of the day after the foot-patrol officers "left," theoretically providing potential offenders increased opportunities for crime by reducing the levels of formal surveillance.

\section{References}

Ariel, B., Weinborn, C., \& Sherman, L. W. (2016). "Soft" policing at hot spots-Do police community support officers work? A randomized controlled trial. Journal of Experimental Criminology, 12, 277-317. 
Braga, A., \& Bond, B. (2008). Policing crime and disorder hot spots: A randomized controlled trial. Criminology, 46, 577-607.

Braga, A., Papachristos, A., \& Hureau, D. (2014). The effects of hot spots policing on crime: An updated systematic review and meta-analysis. Justice Quarterly, 31, 633-663.

Braga, A., Welsh, B., \& Schnell, C. (2015). Can policing disorder reduce crime? A systematic review and meta-analysis. Journal of Research in Crime and Delinquency, 52, 567-588.

Eck, J. (2006). When is a bologna sandwich better than sex? A defense of small-n case study evaluations. Journal of Experimental Criminology, 2, 345-362.

Famega, C. (2005). Variation in officer downtime: A review of the research. Policing: An International Journal of Police Strategies \& Management, 28, 388-414.

Floyd et al. v. The City of New York, 959 F.Supp.2d 540 (2013).

Fratello, J., Rengifo, A., Trone, J., \& Velaquez, B. (2013). Coming of age with stop and frisk: Experiences, perceptions, and public safety implications. New York, NY: Vera Institute of Justice.

Groff, E., Ratcliffe, J., Haberman, C., Sorg, E., Joyce, N., \& Taylor, R. (2015). Does what police do at hot spots matter? The Philadelphia policing tactics experiment. Criminology, 53, 23-53.

Haberman, C. (2016). A view inside the "black box" of hot spots policing from a sample of police commanders. Police Quarterly, 19, 488-517.

Jenkins, M., \& DeCarlo, J. (2015). Police leaders in the new community problem-solving era. Durham, NC: Carolina Academic Press.

Kochel, T., \& Weisburd, D. (2017). Assessing community consequences of implementing hot spots policing in residential areas: Findings from a randomized field trial. Journal of Experimental Criminology, 13, 143-170

Nagin, D., Solow, R., \& Lum, C. (2015). Deterrence, criminal opportunities, and police. Criminology, 53, 74-100.

Novak, K., Fox, A., Carr, C., \& Spade, D. (2016). The efficacy of foot patrol in violent places. Journal of Experimental Criminology, 12, 465-475.

Orr, L. (2015). 2014 Rossi award lecture: Beyond internal validity. Evaluation Review, 39, 167-178.

Piza, E., Caplan, J., Kennedy, L., \& Gilchrist, A. (2015). The effects of merging proactive CCTV monitoring with directed police patrol: A randomized controlled trial. Journal of Experimental Criminology, 11, 43-69.

Piza, E., \& O’Hara, B. (2014). Saturation foot patrol in a high-violence area: A quasi-experimental evaluation. Justice Quarterly, 31, 693-718.

Rahr, S., \& Rice, S. (2015). From warriors to guardians: Recommitting American police culture to democratic ideals (Executive Session on Policing and Public Safety, New Perspectives in Policing Series). Washington, DC: National Institute of Justice.

Ratcliffe, J., Taniguchi, T., Groff, E., \& Wood, J. (2011). The Philadelphia foot patrol experiment: A randomized controlled trial of police patrol effectiveness in violent crime hot spots. Criminology, 49, 795-831.

Rengifo, A., \& Fowler, K. (2016). Stop, question, and complain: Citizen grievances against the NYPD and the opacity of police stops across New York City precincts, 2007-2013. Journal of Urban Health, 93, 32-41.

Rosenfeld, R., Deckard, M., \& Blackburn, E. (2014). The effects of directed patrol and selfinitiated enforcement on firearm violence: A randomized controlled study of hot spot policing. Criminology, 52, 428-449.

Schafer, J., Carter, D., Katz-Bannister, A., \& Wells, W. (2006). Decision making in traffic stop encounters: A multivariate analysis of police behavior. Police Quarterly, 9, 184-209. 
Sherman, L., \& Rogan, D. (1995a). Deterrent effects of police raids on crack houses: A randomized controlled experiment. Justice Quarterly, 12, 755-782.

Sherman, L., \& Rogan, D. (1995b). Effects of gun seizures on gun violence: "Hot spots" patrol in Kansas City. Justice Quarterly, 12, 673-694.

Sherman, L., \& Weisburd, D. (1995). General deterrent effects of police patrol in crime "hot spots": A randomized controlled trial. Justice Quarterly, 12, 625-648.

Skogan, W., \& Frydl, K. (2004). Fairness and effectiveness in policing: The evidence (Committee to Review Research on Police Policy and Practices, and Committee on Law and Justice, Division of Behavioral and Social Sciences and Education). Washington, DC: The National Academies Press.

Smith, D., \& Purtell, R. (2007). An empirical assessment of NYPD's “Operation Impact”: A targeted zone crime reduction strategy. New York, NY: Robert F. Wagner Graduate School of Public Service.

Sparrow, M. (2015). Measuring performance in a modern police organization (Executive Session on Policing and Public Safety, New Perspectives in Policing Series). Washington, DC: National Institute of Justice.

Taylor, B., Koper, C., \& Woods, D. (2011). A randomized controlled trial of different policing strategies at hot spots of violent crime. Journal of Experimental Criminology, 7, 149-181.

Telep, C., Mitchell, R., \& Weisburd, D. (2014). How much time should the police spend at crime hot spots? Answers from a police agency directed randomized field trial in Sacramento, California. Justice Quarterly, 31, 905-933.

Terry v. Ohio, 392 U.S. 1. (1968).

Tipton, E., \& Peck, L. (2016). A design-based approach to improve external validity in welfare policy evaluations. Evaluation Review, 41. doi:10.1177/0193841X16655656

U.S. Census Bureau. (2010). United States census, 2010. Retrieved from www.census. gov/2010census/

U.S. Department of Justice Civil Rights Division. (2014). Investigation of the Newark police department. Washington, DC: United States Attorney's Office.

Weisburd, D., \& Eck, J. (2004). What can police do to reduce crime, disorder, and fear? Annals of the American Academy of Political and Social Science, 593, 42-65.

Weisburd, D., \& Green, L. (1995). Policing drug hot spots: The Jersey City drug market analysis experiment. Justice Quarterly, 12, 711-736.

Weisburd, D., Hinkle, J., Famega, C., \& Ready, J. (2011). The possible "backfire" effects of hot spots policing: An experimental assessment of impacts on legitimacy, fear and collective efficacy. Journal of Experimental Criminology, 7, 297-320.

$\mathrm{Wu}, \mathrm{X}$., \& Lum, C. (2016). Measuring the spatial and temporal patterns of police proactivity. Journal of Quantitative Criminology. Advance online publication. doi:10.1007/s10940016-9318-5

\section{Author Biography}

Eric L. Piza is an associate professor at John Jay College of Criminal Justice, City University of New York. Prior to joining academia, he served as the GIS Specialist of the Newark, New Jersey Police Department, responsible for the day-to-day crime analysis and program evaluation activities of the agency. His research focuses on the spatial analysis of crime patterns, crime control technology, and the integration of academic research and police practice. His recent research has appeared in Criminology, Journal of Experimental Criminology, Journal of Quantitative Criminology, Journal of Research in Crime and Delinquency, and Justice Quarterly. 